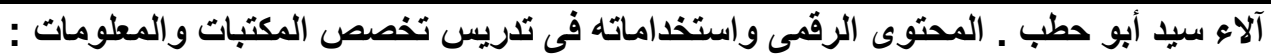

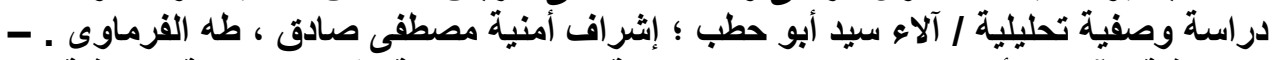

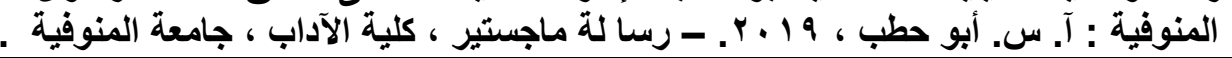

\author{
عرض إنو حئ \\ آلاء سيد أبو حطب \\ معيدة بقسم المكتبات و المعلو الاء ملب مات \\ كلية الاداب - جامعة كفر الثيخ
}

في ظل الثورة العلمية و التكنولوجية المعاصرة، لم يعد المعلم هو المصدر الوحيد للمعرفة، بـل أصبح

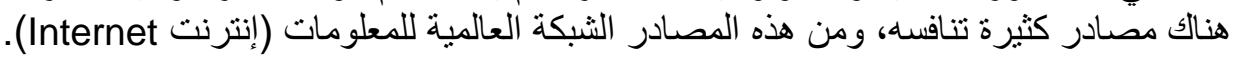

وقد ساهمت البيئة الرقمية التي فرضتها الويب في وجود محتوى رقمي أو كيانات رقمية ذات سمات

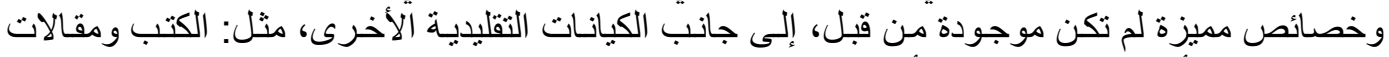

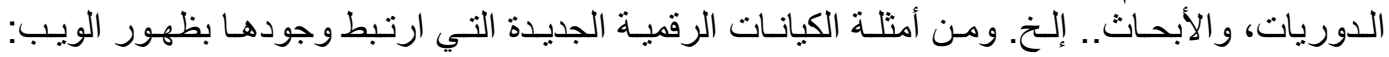

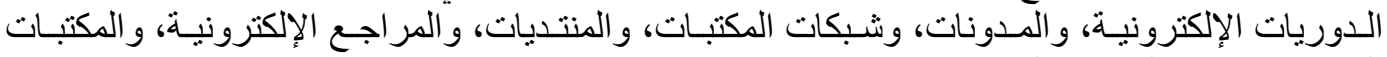
الرقمية، ومواقع الفيديو الإلكترونية.... و غيرنير ها.

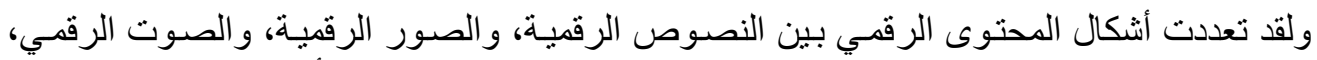

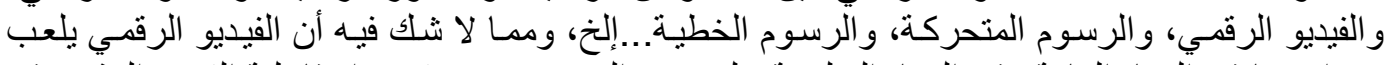

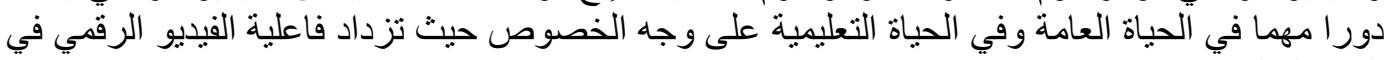
البيئة التعليمية.

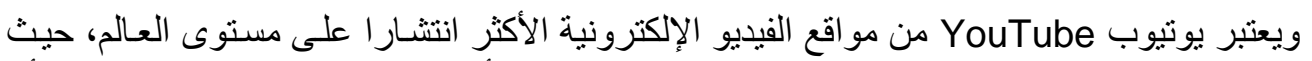

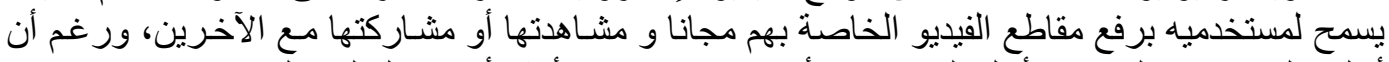

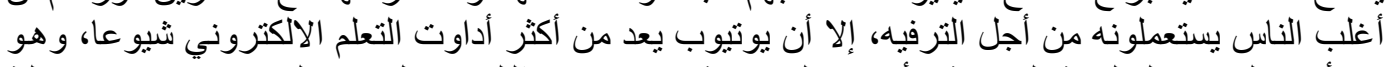

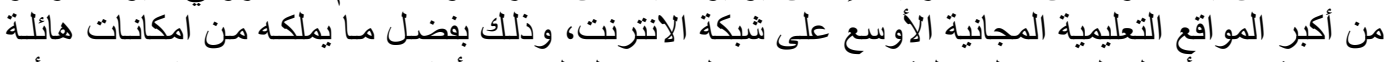

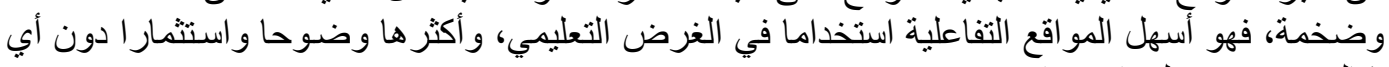
تكاليف تترتب على استخدامه.

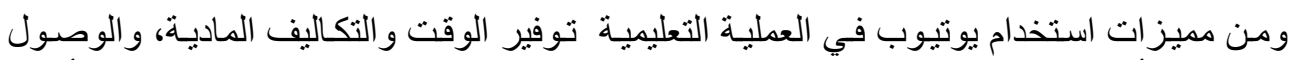

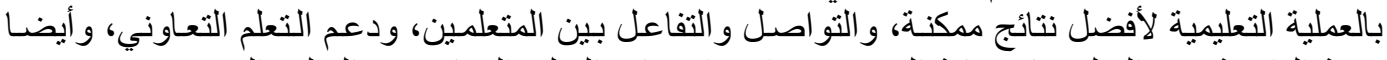

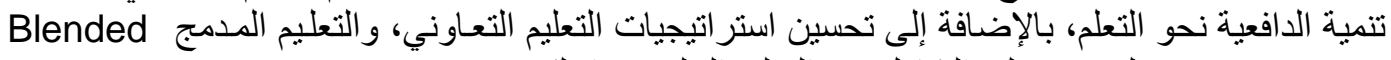

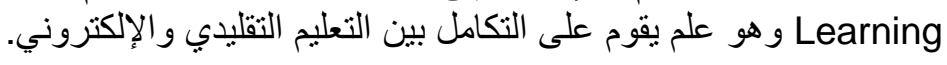
ومع ذلك، لا يمكن استخدام يوتيوب في التعليم كأداة رئيسـة أو بديلة، بـل كأداة مسـاعدة يمكن دمجها

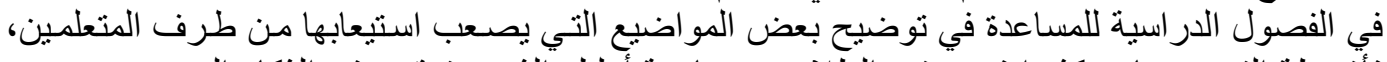

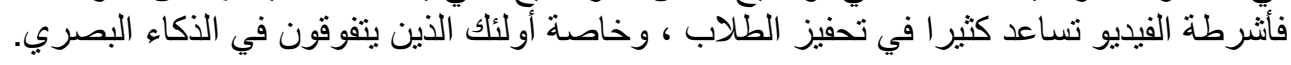

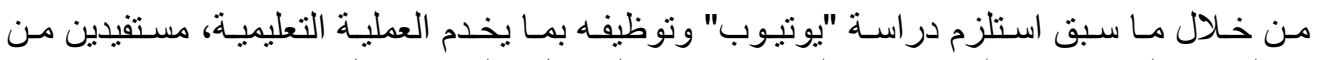

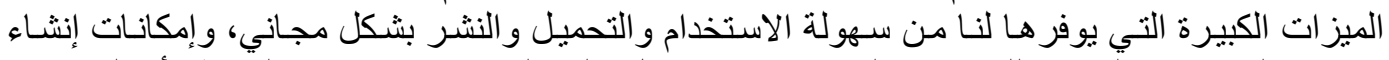

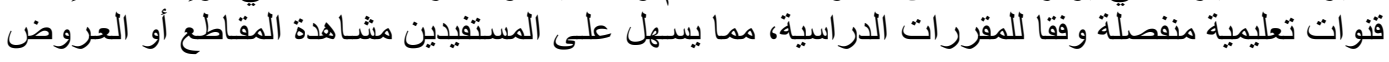


المرئية (الفيديو) على الموقع مباشرة دون الحاجة إلى تحميلها على أجهزتهم، وهذا بدوره يتيح توفرها في أي زمان ومكان.

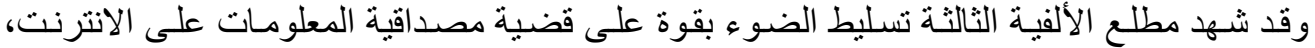

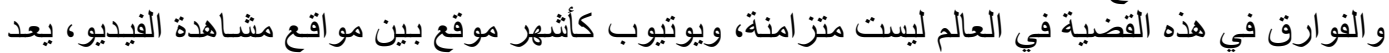

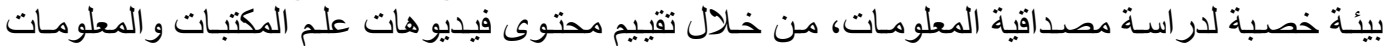
العربية على بوتيوب.

\section{ظاهرة الارراسة:}

إن يوتيوب ليس مجرد موقع إلكتروني ووسيلة للتو اصل بين الناس، بقدر مـا أصبح محطـة يتوقف

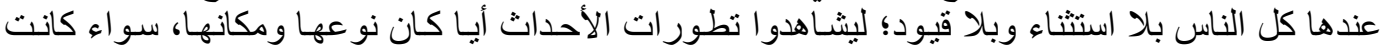

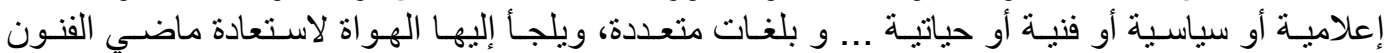

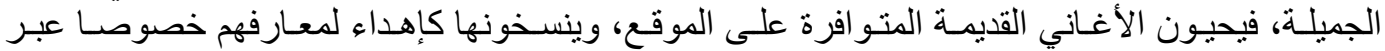

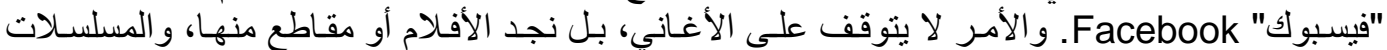
و المسرحيات القديمة و الحديثة.

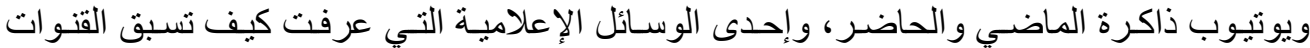
التلفزيونية إلى نقل الخبر وكسب ود الناس فيبدون من خلالها آرائهم بلا رقابة الإعابل أو تدخل .

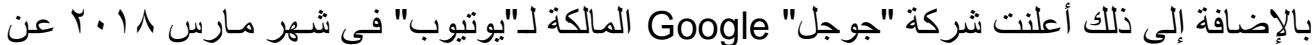

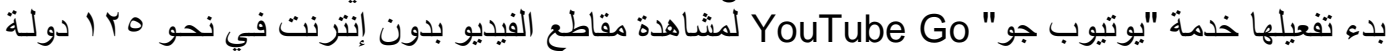

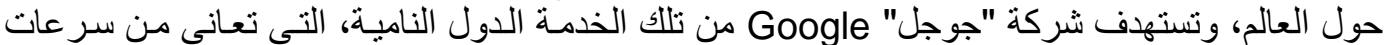

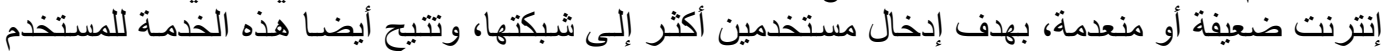

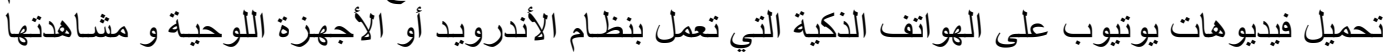
لاحقا بدون الحاجة بالاتصال بالثبكة العنكبوتية.

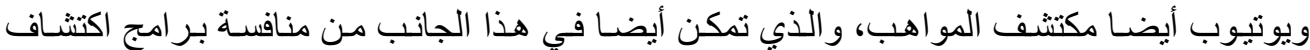

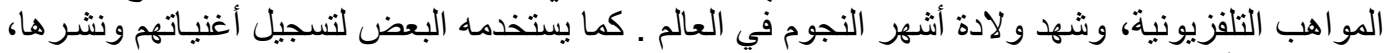

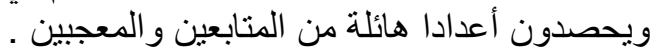

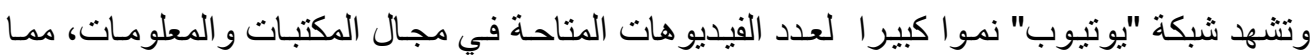

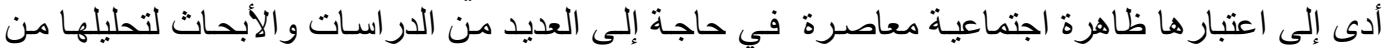

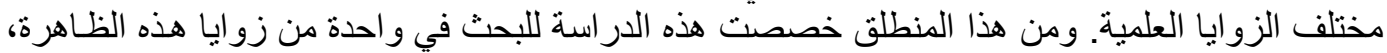

وهى تخصص المكتبات و المعلومات و وارتباطه بشبكة "يوتيوب".

أهداف الدراسة:

لقد سعت هذه الدر اسة إلى تحقيق الأهداف التالية:

( ) در اسة الاتجاهات الموضو عية للمقاطع التعليمية العربية لتخصص المكتبات و المعلومات على يوتيوب.

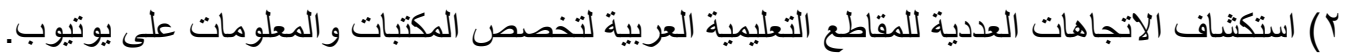

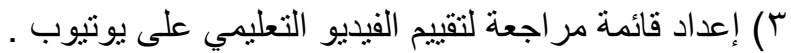
ع) تقييم المقاطع التعليمية العربية لتخصص المكتبات و المعلومـات على يوتيوب في ضو هو عناصر جودة الفيديو التعليمي. 
0) تقييم محتوى المقاطع التعليمية العربية لتخصص المكتبات و المعلومـات على يوتيوب بو اسطة أعضـاء هيئة التدريس لاستثمار ها في التدريس.

حدود الدراسة

تتعلق هذه الدر اسة بفرع من فروع علم المكتبـات و المعلومـات وهو مصسادر المعلومـات الإلكترونيـة،

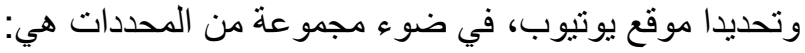

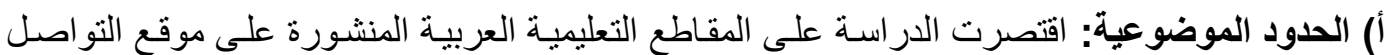

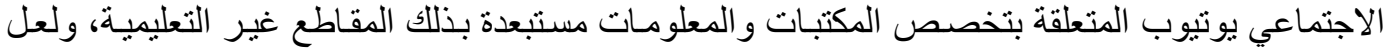

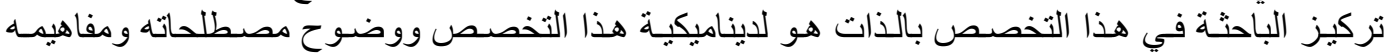

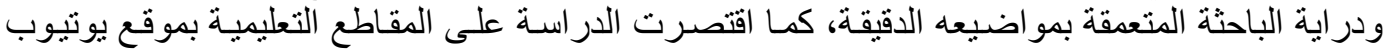

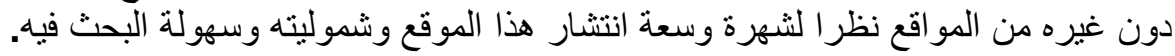

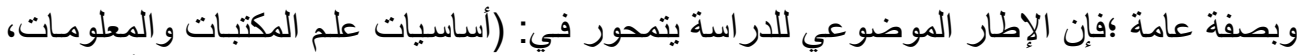

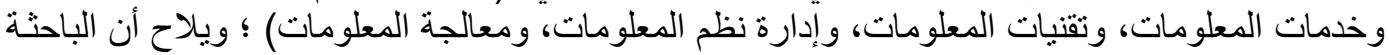

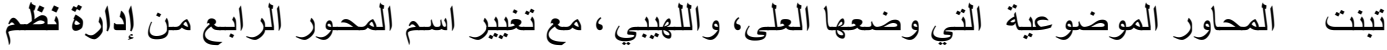

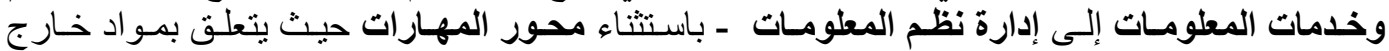

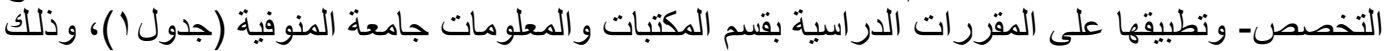

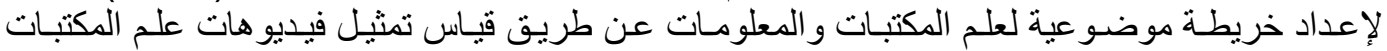

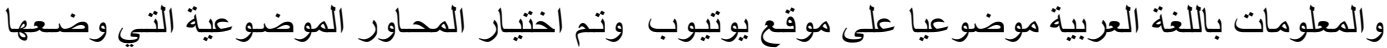

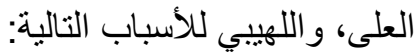

• استعر اضها للتوجهات الحديثة في أقسام المكتبات و المعلومات ومناهجها محليا و عربيا ودوليا، • قيامها باستقر اء احتياجات سوق العمل لخريجي أقسام المكتبات والمعلومات بما يواكب التوجهات

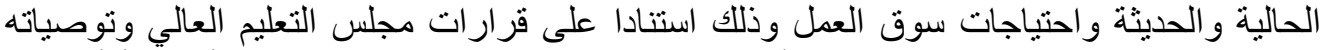
في جلسته السابعة والعشرون والذي أوصى فيها والتها بربط وحصر القبول في الأقسام ألأكاديمية باحتياجات سوق العمل في القطاعين الحكومي و الأهلي.

جدول برنامج قسم المكتبات والمعلومات بجامعة المنوفية طبقا لـ 7 محاور

\begin{tabular}{|c|c|c|c|c|c|}
\hline المهار محور & معالجة محور & محور إدارة & محور تقتيات & محور خدمات المعلومات & محور أساسبيات \\
\hline لغة ألمرنسية & نظمي & نظم قو اعد & نظم تشغيل & و المعلوماتر & مدخل إلى علم المكتبات \\
\hline علم نفس & بناء وتتمية & . & المو اد السمعية & المر اجع العامة & تاريخ الكتب \\
\hline انجليزية & وصفية (1) & إدارة المكبات & والمعنولومات & المعلومات & إحصاء \\
\hline
\end{tabular}


عروض وقراءات متخصصة / اشراف أ أد. أماني زكريا الرمادي

\begin{tabular}{|c|c|c|c|c|c|}
\hline المهار ات & معالجة محور & محور إدارة & محور تقتيات المعلومات & محور خدمات & محور أسماسبات \\
\hline نلخصة أجصوصة & تصنيف (1) & \multirow{8}{*}{ تحليل وتصميم } & نظم استرجاع & مصنادر مرجعية & مدخل الى على \\
\hline أو فارسبة عبة & وصفية (r) & & أرشيف إلكتروني & \multirow{7}{*}{ 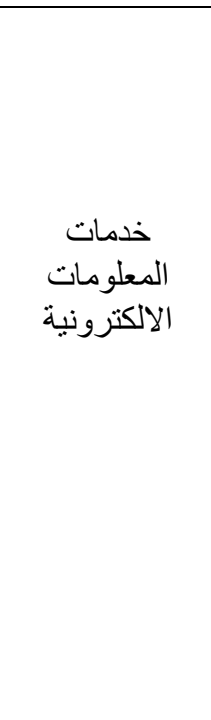 } & طرق البحث \\
\hline لغة عربية & تصنيف(Y) & & برمجة & & مدخل إلى علم \\
\hline انسان & موضورعة & & فتي المكتبات الانترنت & & أرشيف جارى \\
\hline تدريبات & واستخناصن & & \multirow{4}{*}{ تطبيقات الحاسب } & & مكتبات نوعية \\
\hline تشروع تشرج & \multirow{3}{*}{ المعلومات } & & & & مصادر التراث \\
\hline مقدمة في العلوم & & & & & الاتصال العلمي \\
\hline مقدمة في & & & & & مخطوط عربي \\
\hline
\end{tabular}

ب) الحدود اللغوية: تقتصر الدر اسة على فيديوهات علم المكتبات والمعلومـات باللغنة العربية؛ وذللك لدعم

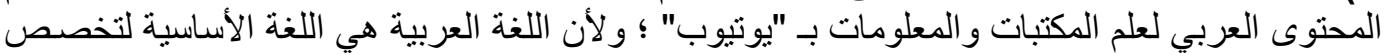

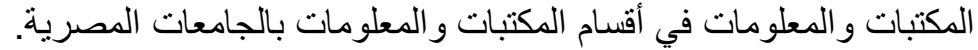

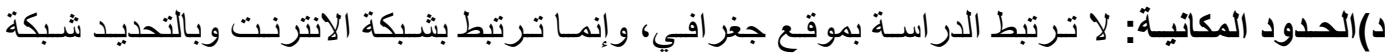

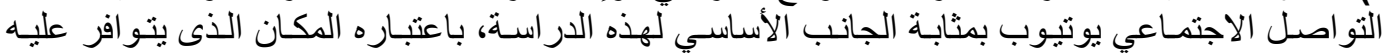

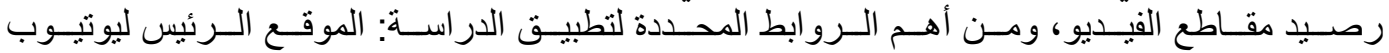

https://www.youtube.com

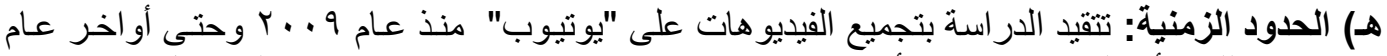

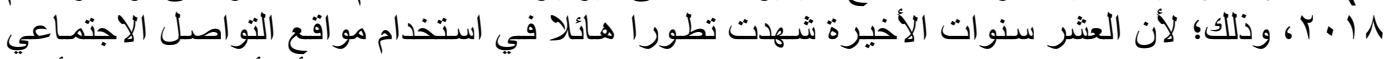

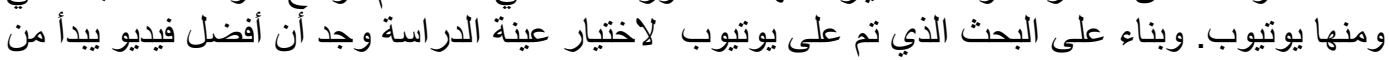

$$
\text { عام } 9 \text {. . }
$$

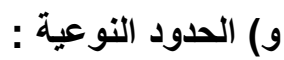

- - تم اختيار الفيديو هات عن طريق عمل تصفية Filter حسب الفيديوهات الأكثر مشـاهدة (

.(Count

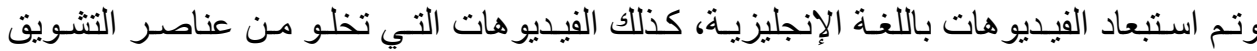

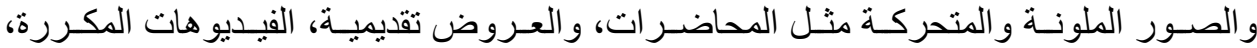

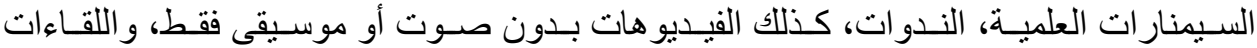


التليفزيونية، المقابلات، فيديوهات علميـة للمرحلـة الابتدائيسة و الإعداديـة و الثانويـة، بالإضـافة إلى

ورش العمل.

\section{منهج الدراسة وأدواتها:}

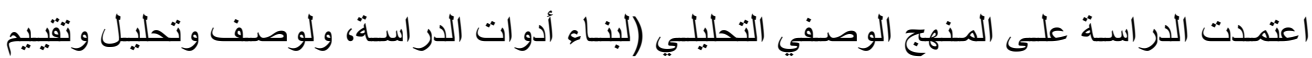

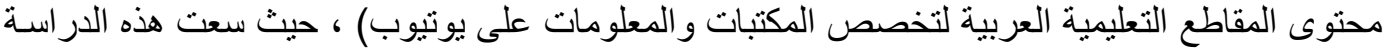

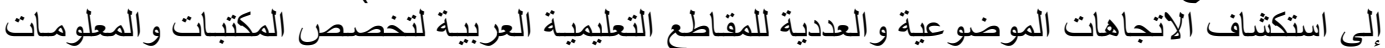

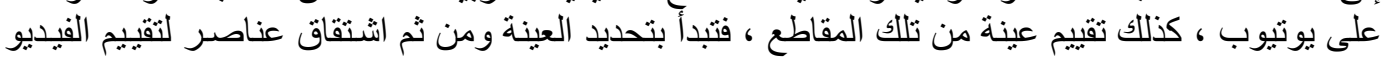
التعليمي، ثم تقييم العينة المستهدفة في هذه الدر اسة وفق فقا للعناصر المثنقة.

أدوات الدراسة:

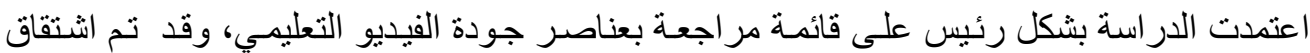

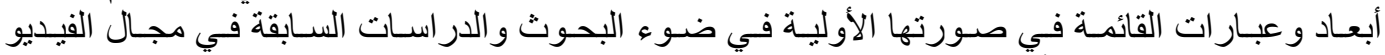

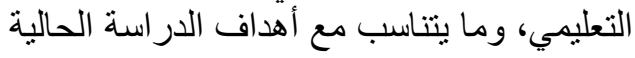

وق تكونت القائمة الأولية من محورين رئيسيين، هما:

المحور الأول: المعـايير التربويـة، والمحسور الثـاني المعـايير التقنيـة، وتضـنت ( • ب) مؤشـرا؛ وتم

اختبار صدق وثبات القائمة بالأساليب الإحصائية المبردة المناسبة.

عينة الار اسةة:

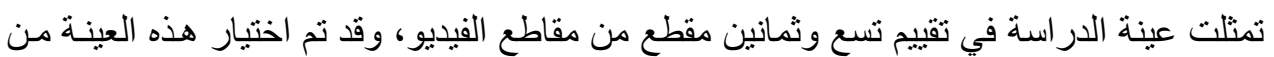

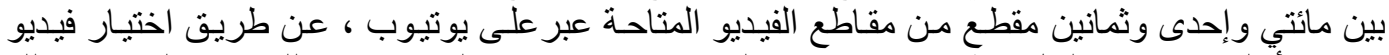

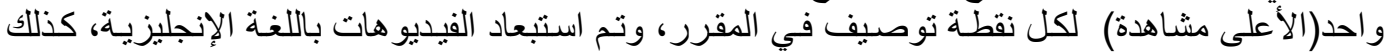

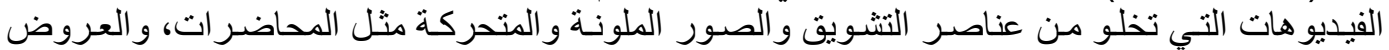

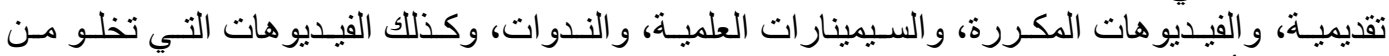

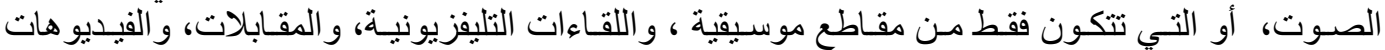

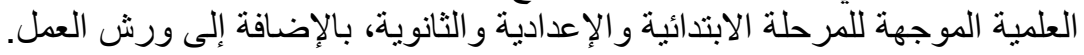

فصول الاراسة

اشتملت الدر اسة على مقدمة، وثثلاثة فصول ، فيما بلي بيانها:

المقدمة المنهرجية

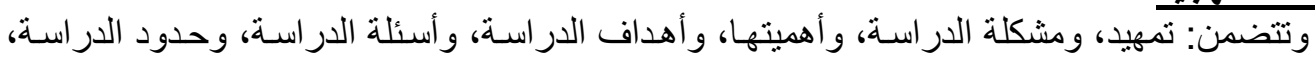

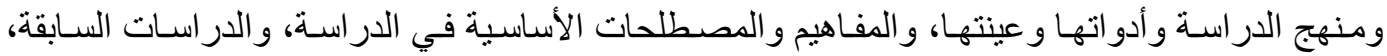

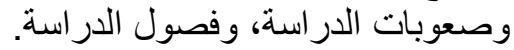

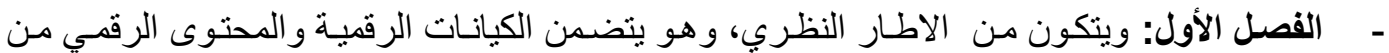

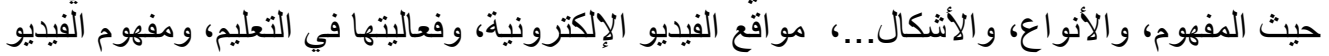

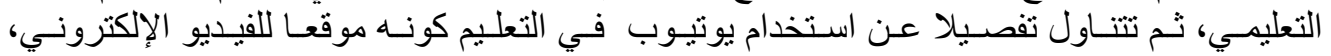

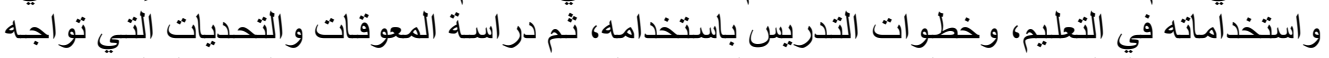
استخدامه في التعليم، وتختتم الباحثة الإطار النظري بالحديث عن عناصر جودة الفيديو التعليمي. 
ـ الفصل الثاني: تخصص المكتبات والمعلومات على يوتيوب.

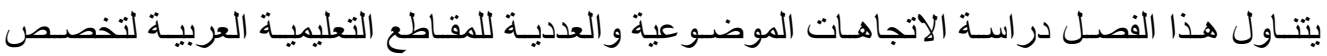

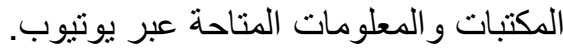

الفصل الثالث: تقييم المقاطع التعليمية العربية لتخصص المكتبات والمعلومات على يوتيوب

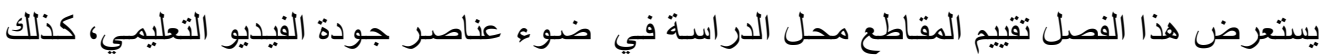
تقييم تلك الفيديوهات من وجهة نظر أعضاء هيئة التدريس لاستثمار ها في التدريس.

أبرز النتائج والتوصيات:

انتهت الدراسة إلى عدة نتائج ، لعل أبرزها ما يلي:

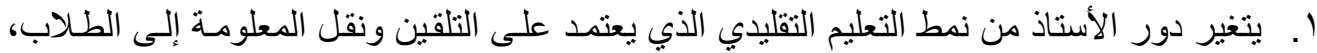

إلى دور المرشد و الموجـه والمر اقب لعمليات تعلم وتعليم الطالب باستخدام الفيديو التعليمي في ولفي

مجال التخصص، بما ينمى لديهم أنماط التفكير و المهار ات الفنية و والنقدية و التعلم الفئ الذاتي.

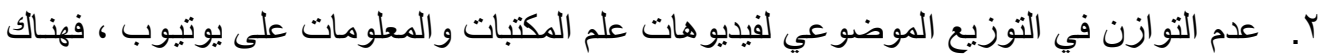

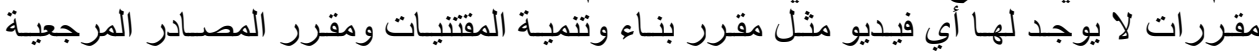

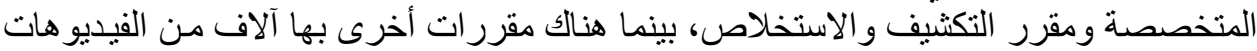

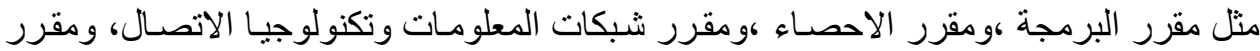

نظم تشغيل الحاسب.

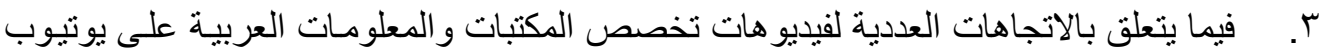

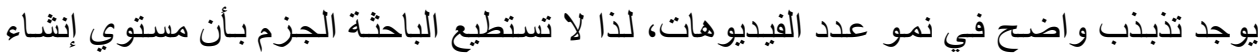

الفيديو هات في تزايد مستمر أو العكس.

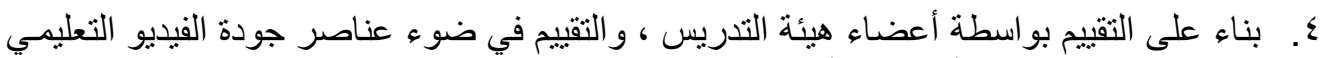

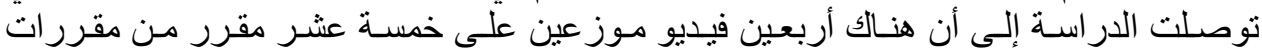

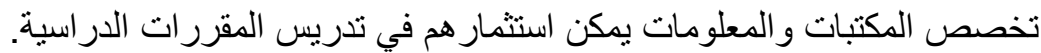

كما انتهت الاراسة لعدد من التوصيات ، فيما يلي أبرزها:

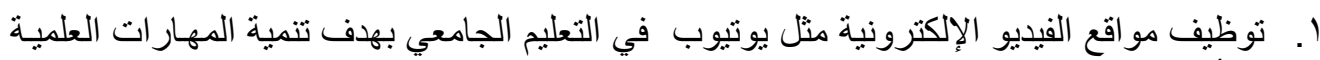
والأدائية المراد اكسابها للطلبة.

r. ـ انضـمام الجامعـات المصـرية والعربيـة إلى قنـاة بوتيوب التعليميـة EDU ، ونشـر المحاضـرات

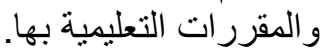

ب. ضرورة دعم المحتوى العربي على يوتيوب ، وتحديدا تخصص المكتبات و المعلومات، وتكاتف الأكاديميين لتصحيح صورة دعم التخصص في العالم. 